\title{
Validation of the Mobile Phone Addiction among Under-graduate Students Using SAS
}

\author{
Chand Badshah S B V J ${ }^{\# 1}$, U.Babu*1, K.Arun ${ }^{\# 2}$, M.Gopala Krishna*2, M. Peeraiah ${ }^{\# 3}$ \\ ${ }^{\# 1}$ Assistant Professor, Department of M.E, AITS, Tirupati, Andhra Pradesh, India. \\ ${ }^{* 1}$ Assistant Professor, Department of M.E, AITS, Tirupati, Andhra Pradesh, India \\ ${ }^{\# 2}$ Assistant Professor, Department of M.E, SVCE, Tirupati, Andhra Pradesh, India. \\ ${ }^{* 2}$ Assistant Professor, Department of M.E, SVCE, Tirupati, Andhra Pradesh, India. \\ \#3 Assistant Professor, Department of M.E, SVCE, Tirupati, Andhra Pradesh, India. \\ 11 chandbadshah36@gmail.com, ${ }^{1}$ babu.uppalapati@gmail.com, ${ }^{2}$ arunk4u@gmail.com, \\ 2.gopala523@gmail.com, ${ }^{3}$ shreepeeru@gmail.com
}

\begin{abstract}
We explored the factors influencing mobile phone addiction in under-graduate students. This investigation is based on age, gender, social status, monthly income and hours of daily phone use time, sending and receiving text messages on weekends, monthly call charges ,internet usage, Wi-Fi usage, media specific factors, social networking, performance in academics etc. To collect data, questionnaire probing mobile phone addiction consisting of several factors were distributed among students. The data were analyzed using the SAS Enterprise guide (ANOVA). The findings are divided as heavy users, average users and light users. There was a statistical difference between females and males were found. These scales were applied for 527 students who are from different Departments of AITS, Tirupati. We found that cell phone use appears to be a sedentary leisure behavior and inserts loneliness.
\end{abstract}

Keywords-ANOVA, Under-graduate students, Addiction, Mobile phone, SAS.

\section{INTRODUCTION}

Communal areas providing $\mathrm{Wi}-\mathrm{Fi}$ service within universities enable individuals to access to the Internet via smart phones, PDAs and iPods as well as desktops which in turn influences the use of the Internet both negatively and positively[1]. Especially the students studying at departments related to computers and informatics are exposed to the Internet as the departments by nature require doing so and therefore these students are more likely to turn into problematic Internet users.

The order of smart phone addiction indices were as follows: overuse of smart phone, the technological dimension, the psychological-social dimension, preoccupation with smart phones, and the health dimension [6]. Significant gender differences were found in the degree of addiction on the whole questionnaire and all of its dimensions with the exception of the technological dimension in favor of males. Significant differences by social status were found in favor of the unmarried. Bachelor degree students were found to have the highest degree of addiction. Significant differences by hours of daily use were also detected in favor of participants using the smart phone for more than $4 \mathrm{~h}$ a day. As to the monthly income dimension, significant differences were found on the health dimension in favor of participants with lower monthly income.

Cell phones are now almost indispensable in our daily life, but the results of our experiment suggest that cell phone use makes pedestrians inattentive to hazards and increases the risk of traffic accidents and possible casualties in railway stations [3]. Talking on a hand-held cell phone while driving an automobile is banned by traffic law in Japan. We may need some kind of prohibition or restriction on walking while using a cell phone in railway stations and busy streets.

The attitudes regarding the mobile phone usage has displayed no differentiation in any sub dimension according to age. Students with high income levels find the mobile phone more beneficial in daily life compared to students with low income levels [7]. Students with high academic success levels know the rules regarding the mobile phone usage better compared to students with low levels of academic success. It has been determined that students who possess mobile phones show more interest in them and know the rules regarding their usage better compared to ones who don't. However, students who don't have mobile phones have indicated that mobile phones are harmful more strongly compared to students who have mobile phones.

Expectedly the traditional calling and use of SMS were the most heavily used features, and were used on a daily basis [9]. These were followed by the calendar feature, which was used by more than half of the respondents on a daily basis. The features Internet, music, notes, and calculator experienced medium usage meaning that half or most respondents used the features 2-3 times a week. All other features (E-mail, pictures, camera + video, games, and MMS) had a lighter usage than this. There were gender differences in the usage of the features as well. Female users were significantly heavier users of calendar, Internet, music, and E-mail. 
The behavior of university students (as representatives of young people and important and immediate future consumers) with regard to their use and disposal of mobile phones has been evaluated and the study has established that many students replace their phones at least once a year, often replacing broken phones or getting upgrades from network operators [8]. Remaining "fashionable" and a desire to have a handset with a longer battery life are other main reasons for the rapid replacement of phones among students. Almost 6 in 10 replaced phones are not sent to reuse or recycling operations but are instead stockpiled by the students with "keeping a backup phone" as the main reason for this practice.

Loneliness of university students was examined in the current study in terms of mobile phone addiction, daily use of mobile phone and gender [2]. When literature is analyzed, the literature has revealed that studies on mobile phone addiction do not have too much background. In addition, studies on mobile phone addiction related to loneliness are quite a few.

With the growing amount of research on the use of technology, especially the mobile phones, the paucity of research in the area of mobile phone use that focus on the reasons why students use their mobile phones during lecture periods is somewhat surprising. Findings from the previous studies have documented that students continue to use their mobile phones during lecture periods even in classes where its use is banned [5].

Social extraversion and anxiety have positive effects on mobile phone addiction, and self-esteem has negative effects on mobile phone addiction and Mobile phone addiction has a positive predictive effect on mobile phone usage behavior [10]. The results of this study identify personal psychological characteristics of Taiwanese female university students which can significantly predict mobile phone addiction; female university students with mobile phone addiction will make more phone calls and send more text messages.

As mobile phones become increasingly ubiquitous, the functional capacity of the mobile phone continues to diversify. Ownership and use of the mobile are most prevalent in young people. It is found that the mobile phone is an integral tool in the everyday life of young people with many advantages relating to use [4]. These are discussed with reference to information that is communicated by calling or texting. However, a level of caution in use is recommended due to concerns expressed by participants.

\section{METHODOLOGIES}

\section{A. Participants}

The sample group of this study is 527 students from different Departments of Faculty of Engineering at AITS. $372(\% 70.5)$ of the students are male, $155(\% 29.5)$ of them are female, average age of students is 20 . All of participants had mobile phone (\%100).

Mobile phones offer many possibilities presented by the Internet and computers [7]. While computers and the Internet may cause loneliness of individuals, may mobile phone cause loneliness of individuals? In this context the purpose of the study is to examine loneliness of university students in terms of daily use of mobile phone, mobile phone addiction and gender.

B. Instruments

Many instruments such as ANOVA, SAS Enterprise Guide and The revised UCLA Loneliness Scale: Concurrent and discriminated validity evidence are used. Survey model is used for this research. To collect data; personnel information form, problematic mobile phone use scale, and UCLA-loneliness scale were applied for 527 students who are from different Departments of AITS, Tirupati [1]. To analyse these data; correlation, $t$ test, Analysis of variance (ANOVA) analysis and UCLA Loneliness were used. Complete data interpretation done in SAS Enterprise Guide.

\section{Procedure}

Survey model is used for this research and to collect data; personal information form, correlation, Ttest, ANOVA and UCLA-LS, NBA-LS was applied to 527 students from different Departments of AITS at Tirupati.

D. Research Tools and Support

SAS Enterprise Guide is a powerful Microsoft Windows client application that provides a guided mechanism to exploit the power of SAS and publish dynamic results throughout the organization. The new DATA Step Debugger is a tool that enables you to find logic errors in a DATA step program [9]. With the DATA Step Debugger, you can watch the variable values in a program change as the program runs. It helps in executing the program line by line, and also set specific breakpoints in the program.

\section{E. Research Questions}

Based on the above discussion, the current paper tries to answer the following questions [2]-[7]:

1. Is there any significant relationship between mobile device usages to improve Technical content reading proficiency?

2. Does Gender affect the impact of mobile device usage on Technical content reading proficiency? 
3. What is the impact of using mobile phones to learn Technical content and to improve skills?

4. Does Monthly Income status shows effect on usage of mobile phone?

5. Does Mobile phone usage improves the academic performance of students?

The following demographic information was considered as independent variables and was obtained from the first seven questions of the questionnaires.

- Gender

- Usability of mobile phone/s application in the class

- Relationship of Mobile Application with the teenagers Technical content Grasping

- Social networking

- Performance in academics

- Daily Internet Usage

- Monthly call Charges

\section{FINDINGS}

The findings of the correlation analysis regarding the relationship between the no of hours working on the mobile phone by the students/day and the factors of the scale can be observed in the Table 1 below.

Table I The correlation analysis regarding the relationship between the no of hours working on the mobile phone/day by the students and the factors of the scale

\begin{tabular}{|l|l|l|l|l|l|l|l|l|l|l|}
\hline No.of hours/Day & 1 & 2 & 3 & 4 & 5 & 6 & 7 & 8 & 9 & 10 \\
\hline $\begin{array}{l}\text { Correlation } \\
\text { factors }\end{array}$ & 546 & 280 & 320 & 350 & 370 & 390 & 407 & 425 & 450 & 475 \\
\hline
\end{tabular}

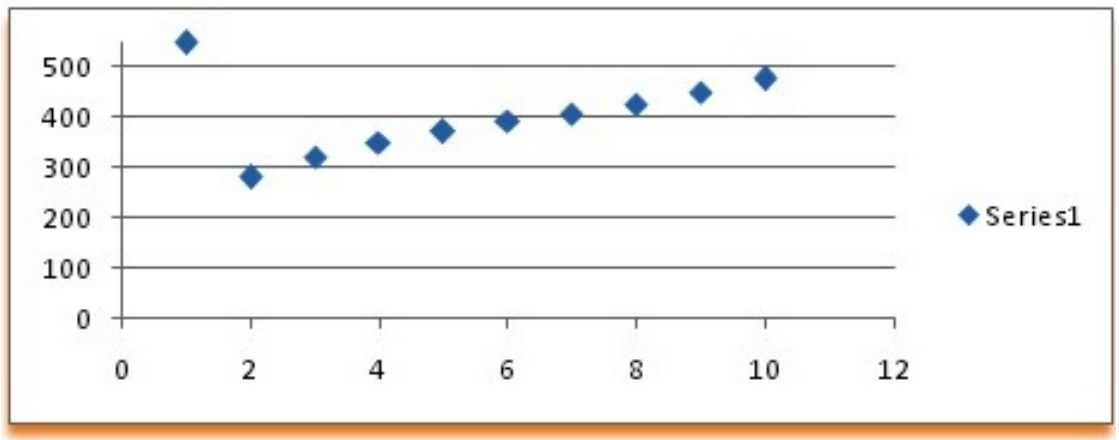

Fig.1. The correlation analysis regarding the relationship between the no of hours working on the mobile phone/day by the students and the factors of the scale

The Findings of the t-test analysis regarding the relationship between the age of the students and the factors of the scale can be observed in the Table 2 below.

TABLE II [7] t-test analysis regarding the relationship between the age of the students and the factors of the scale

\begin{tabular}{|l|l|l|l|l|l|l|l|l|}
\hline Factors & Age & $\mathbf{N}$ & $\mathbf{X}$ & ss & sh & sd & t & p \\
\hline Gender & 18 & 175 & 24.01 & 17.00 & 0.25 & 366 & 1.004 & 0.416 \\
\hline $\begin{array}{l}\text { Usability of mobile phone/s application } \\
\text { in the class }\end{array}$ & 19 & 120 & 23.02 & 15.00 & 0.24 & 366 & 2.004 & 0.402 \\
\hline $\begin{array}{l}\text { Relationship of Mobile Application with } \\
\text { the teenagers Technical content } \\
\text { Grasping }\end{array}$ & 20 & 125 & 22.01 & 14.02 & 0.23 & 366 & 1.002 & 0.402 \\
\hline Social networking & 21 & 128 & 20.01 & 13.06 & 0.22 & 366 & 1.43 & 0.402 \\
\hline Performance in academics & 22 & 130 & 19.02 & 12.03 & 0.21 & 366 & 2.02 & 0.000 \\
\hline Daily Internet Usage & 23 & 134 & 18.02 & 11.02 & 0.20 & 366 & 2.33 & 0.000 \\
\hline Monthly call Charges & 24 & 137 & 17.03 & 07.03 & 0.17 & 366 & 2.45 & 0.203 \\
\hline
\end{tabular}

The Findings of the t-test analysis regarding the relationship between the age of the students and the factors of the scale can be observed in the Table 3 below. 
Table III [11] t-test analysis regarding the relationship between the possession of smart phones and the factors of the scale

\begin{tabular}{|l|c|c|c|c|c|c|c|c|}
\hline Factors & $\begin{array}{c}\text { Possession of } \\
\text { smart phones }\end{array}$ & $\mathbf{N}$ & $\mathbf{X}$ & $\mathbf{s S}$ & $\mathbf{s h}$ & $\mathbf{s d}$ & $\mathbf{t}$ & $\mathbf{p}$ \\
\hline Gender & YES & 119 & 17.01 & 11.00 & 0.19 & 366 & 2.003 & 0.117 \\
\hline $\begin{array}{l}\text { Usability of mobile phone/s } \\
\text { application in the class }\end{array}$ & $\begin{array}{l}\text { YES } \\
\text { NO }\end{array}$ & 85 & 16.02 & 10.00 & 0.18 & 366 & 3.004 & 0.102 \\
\hline $\begin{array}{l}\text { Relationship of Mobile } \\
\text { Application with the teenagers } \\
\text { Technical content Grasping }\end{array}$ & $\begin{array}{l}\text { YES } \\
\text { NO }\end{array}$ & 90 & 15.01 & 09.02 & 0.17 & 366 & 1.022 & 0.101 \\
\hline Social networking & $\begin{array}{l}\text { YES } \\
\text { NO }\end{array}$ & 95 & 14.01 & 08.06 & 0.16 & 366 & 1.120 & 0.000 \\
\hline Performance in academics & NO & 100 & 13.02 & 07.03 & 0.15 & 366 & 0.089 & 0.900 \\
\hline YES & $\begin{array}{l}\text { YES } \\
\text { NO }\end{array}$ & 105 & 11.02 & 06.02 & 0.14 & 366 & 1.203 & 0.890 \\
\hline Monthly call Charges & YES & 137 & 17.03 & 07.03 & 0.12 & 366 & 2.345 & 0.800 \\
\hline
\end{tabular}

The findings of the ANOVA test regarding the relationship between mindset of the students and the factors of the scale can be observed in the Table IV below.

TABLE IV [7] ANOVA test regarding the relationship between mindset of the students and the factors of the scale

\begin{tabular}{|c|c|c|c|c|c|c|c|}
\hline Factors & Mind set of students & $\mathbf{N}$ & $\mathbf{x}$ & Ss & sh & $\mathbf{F}$ & $\mathbf{P}$ \\
\hline \multirow{5}{*}{ Gender } & Not Good(1) & 53 & 7.82 & 2.85 & 0.85 & \multirow{5}{*}{0.50} & \multirow{5}{*}{0.547} \\
\hline & $\operatorname{Good}(2)$ & 23 & 7.23 & 2.12 & 0.25 & & \\
\hline & Very Good(3) & 380 & 7.35 & 2.35 & 0.50 & & \\
\hline & Excellent(4) & 38 & 7.25 & 2.10 & 0.10 & & \\
\hline & Marvellous(5) & 50 & 7.36 & 2.20 & 0.20 & & \\
\hline \multirow{5}{*}{$\begin{array}{l}\text { Usability of mobile phone/s } \\
\text { application in the class }\end{array}$} & Not Good(1) & 41 & 5.90 & 2.86 & 0.90 & \multirow{5}{*}{0.23} & \multirow{5}{*}{0.456} \\
\hline & $\operatorname{Good}(2)$ & 56 & 5.36 & 1.25 & 0.25 & & \\
\hline & Very Good(3) & 390 & 5.23 & 1.28 & 0.23 & & \\
\hline & Excellent(4) & 143 & 5.12 & 1.36 & 0.26 & & \\
\hline & Marvellous(5) & 50 & 5.25 & 1.25 & 0.40 & & \\
\hline \multirow{5}{*}{$\begin{array}{l}\text { Relationship of Mobile } \\
\text { Application with the } \\
\text { teenagers Technical content } \\
\text { Grasping }\end{array}$} & Not Good(1) & 25 & 7.85 & 2.90 & 0.25 & \multirow{5}{*}{0.10} & \multirow{5}{*}{0.450} \\
\hline & $\operatorname{Good}(2)$ & 40 & 7.42 & 2.36 & 0.90 & & \\
\hline & Very Good(3) & 415 & 7.35 & 2.35 & 0.35 & & \\
\hline & Excellent(4) & 30 & 7.23 & 1.85 & 0.30 & & \\
\hline & Marvellous(5) & 20 & 7.12 & 1.28 & 0.20 & & \\
\hline \multirow{5}{*}{ Social networking } & Not Good(1) & 43 & 7.85 & 2.98 & 0.85 & \multirow{5}{*}{0.10} & \multirow{5}{*}{0.256} \\
\hline & $\operatorname{Good}(2)$ & 23 & 7.23 & 2.56 & 0.20 & & \\
\hline & Very Good(3) & 400 & 7.42 & 2.36 & 0.50 & & \\
\hline & Excellent(4) & 20 & 7.38 & 2.03 & 0.30 & & \\
\hline & Marvellous(5) & 10 & 7.12 & 2.02 & 0.56 & & \\
\hline \multirow{5}{*}{ Performance in academics } & Not Good(1) & 50 & 9.90 & 1.85 & 0.20 & \multirow{5}{*}{0.10} & \multirow{5}{*}{0.521} \\
\hline & $\operatorname{Good}(2)$ & 60 & 9.82 & 1.50 & 0.80 & & \\
\hline & Very Good(3) & 400 & 9.56 & 1.25 & 0.30 & & \\
\hline & Excellent(4) & 20 & 9.32 & 1.20 & 0.56 & & \\
\hline & Marvellous(5) & 20 & 9.56 & 1.25 & 0.20 & & \\
\hline \multirow{5}{*}{ Daily Internet Usage } & Not Good(1) & 20 & 8.52 & 1.90 & 0.80 & \multirow{5}{*}{0.23} & \multirow{5}{*}{0.256} \\
\hline & $\operatorname{Good}(2)$ & 30 & 8.46 & 1.80 & 0.23 & & \\
\hline & Very Good(3) & 415 & 8.25 & 1.25 & 0.21 & & \\
\hline & Excellent(4) & 50 & 8.25 & 1.23 & 0.56 & & \\
\hline & Marvellous(5) & 40 & 8.12 & 1.25 & 0.20 & & \\
\hline \multirow{5}{*}{ Monthly call Charges } & Not Good(1) & 30 & 7.90 & 1.90 & 0.90 & \multirow{5}{*}{0.90} & \multirow{5}{*}{0.407} \\
\hline & $\operatorname{Good}(2)$ & 90 & 7.54 & 1.85 & 0.56 & & \\
\hline & Very Good(3) & 407 & 7.27 & 1.25 & 0.20 & & \\
\hline & Excellent $(4)$ & 10 & 7.30 & 1.23 & 0.23 & & \\
\hline & Marvellous(5) & 10 & 7.27 & 1.10 & 0.33 & & \\
\hline
\end{tabular}



Tirupati.

UCLA-LS were applied to 527 students from different Departments of Faculty of Engineering at AITS,

TABLE V Means, standard deviations, t, F values of loneliness, Addiction, Gender (Male: 372, Female: 155), Performance towards loneliness of college students according to performance

\begin{tabular}{|l|l|l|l|l|}
\hline UCLA-LS & $\mathbf{1}($ Mean)X & 2(Standard Deviation)Sd & BranBach's Beta & Chhab's Alpha \\
\hline UCLA-LS(t-values) & 90,5 & 39,5 & 0.175 & 0.000 \\
NBA-LS & 407,7 & 200,7 & 0.255 & 0.0011 \\
\hline UCLA-LS(F-values) & 35,5 & 38,5 & 0.125 & 0.0011 \\
NBA-LS & 350,5 & 150,4 & 0.407 & 0.0001 \\
\hline UCLA-LS(Addiction) & 25,2 & 90,5 & 0.50 & 0.0111 \\
NBA-LS & 399,7 & 250,3 & 0.102 & 0.111 \\
\hline UCLA-LS(Gender) & 20,3 & 10,3 & 0.001 & 0.0000 \\
NBA-LS & 350,7 & 230,5 & 0.203 & 0.0201 \\
\hline UCLA-LS(Performance) & 140,3 & 25,3 & 0.023 & 0.0001 \\
NBA-LS & 360,5 & 200,7 & 0.021 & 0.0002 \\
\hline
\end{tabular}

\section{DISCUSSIONS}

In this research the female respondents seem to use the calendar, Internet, music, and E-mail significantly more than the male respondents. As far as the feature preferences are concerned the female respondents seem to appreciate more price, aesthetics, design, standard processes and parts used, local language capability, safety in terms of radiation, and ringing tones. Male respondents on the other hand appreciate significantly more the use of business services. Also the broad feature preferences were compared to the actual usage areas of the cell phone.

As to the monthly income dimension, significant differences were found on the health dimension in favor of participants with lower monthly income. Bachelor degree students were found to have the highest degree of addiction. Significant differences by hours of daily use were also detected in favor of participants using the Smartphone for more than $4 \mathrm{~h}$ a day. The order of Smartphone addiction indices were as follows: overuse of Smartphone, the technological dimension, the psychological-social dimension, preoccupation with Smartphone's, and the health dimension. Significant gender differences were found in the degree of addiction on the whole questionnaire and all of its dimensions with the exception of the technological dimension in favor of males.

\section{CONCLUSIONS AND RECOMMENDATION}

Findings revealed that addiction percentage among participants was $45.27 \%$. Male student's addiction percentage is almost $72 \%$. The results confirm the seven-factor solution of the smart phone Addiction Test. This situation may also make students lonely. Although mobile phones and the Internet are used as communication tools, excessive use of these technological tools causes individuals to become addicted. Even communication tools may cause non-communication situations. Individuals who are under these circumstances can be supported to receive the help of individual or group counseling in order to make use of such technological tools in accordance with their needs.

When loneliness of university students was examined according to gender, loneliness scores of male students were found higher than the scores of female students. These mobile phones increase the depression levels in students and make their behavior as rapid radicals.

Based on these findings that have been reached, it can be suggested that Union Government of Technology, Education and research may take actions in order to intensify the level of awareness in students, parents, faculty members, staff and administrators with a focus on the gender and age of students start using smart phones, the harms and gains of mobile phones and the rules regarding the usage of smart phones. This research strongly recommends to all the female students to use smart phones and to dignify the entire (through digital) system and surroundings. More Start-ups are required in this area of research. 


\section{REFERENCES}

[1] Aysegul Ozdemir Topaloglu, Murat Topaloglu, "The Study of Computer Technology and Information Systems Students Problematic Internet Use Levels and Predictiveness with the Regard to Various Variables" Procedia - Social and Behavioral Sciences, Volume 182, 13 May 2015, Pages 637-644.

[2] Çetin Tan, Mustafa Pamuk, Ayşenur Dönder, "Loneliness and Mobile Phone" Procedia - Social and Behavioral Sciences, Volume 103, 26 November 2013, Pages 606-611.

[3] Maryam Gheytasi, Akbar Azizifar, Habib Gowhary, "The Effect of Smartphone on the Reading Comprehension Proficiency of Iranian EFL Learners" Procedia - Social and Behavioral Sciences, Volume 199, 3 August 2015, Pages 225-230.

[4] J. Fowler, J. Noyes "From Dialing to Tapping: University Students Report on Mobile Phone Use" Procedia Manufacturing, Volume 3, 2015, Pages 4716-4723.

[5] Fritz, Mike "Comparing more than two means: two factors ANOVA with independent samples; the important role of interaction", pg.187-204, 2015.

[6] F. Prat, M.E. Gras, M. Planes, B. González-Iglesias, M.J.M. Sullman "Psychological predictors of texting while driving among university students Transportation Research Part F: Traffic Psychology and Behaviour”, Volume34, October2015, Pages 76-8.

[7] Z. Nurdan Baysal, Senem Seda Şahenk, Yeşim Özden Hazneci, “Evaluation of the primary school level students' attitudes towards mobile phones Procedia - Social and Behavioral Sciences", Volume 2, Issue 2, 2010, Pages 4279-4284.

[8] Russell, D., Peplau, L.A., \& Cutrona, C.E. (1980) “The revised UCLA Loneliness Scale: Concurrent and discriminant validity evidence". Journal of Personality and Social Psychology, 39, 472-480.

[9] Matti Haverila, "Cell phone usage and broad feature preferences: A study among Finnish undergraduate students Telematics and Informatics", Volume 30, Issue 2, May 2013, Pages 177-188.

[10] Ibrahim Taymur, Ersin Budak, Hakan Demirci, Hatice Alkan Akdağ, Buket Belkız Güngör, Kadir Özdel "A study of the relationship between internet addiction, psychopathology and dysfunctional beliefs Computers in Human Behavior", Volume 61, August 2016, Pages 532-536.

[11] Suliman S. Aljomaa, Mohammad F. Al.Qudah, Ismael S. Albursan, Salaheldin F. Bakhiet, Adel S. Abduljabbar, "Smartphone addiction among university students in the light of some variables", Computers in Human Behavior, Volume 61, 2016, Pages 155-164.

\section{AUTHOR PROFILE}

Chandbadshah S B V J working as an Assistant Professor, Department of Mechanical Engineering, Annamacharya Institute of Technology and Sciences, Tirupati, Andhra Pradesh, 517520, India.

U.Babu working as an Assistant Professor, Department of Mechanical Engineering, Annamacharya Institute of Technology and Sciences, Tirupati, Andhra Pradesh, 517520, India.

K.Arun working as an Assistant Professor, Department of Mechanical Engineering, S.V. College of Engineering, Tirupati, Andhra Pradesh, 517520, India.

M.Gopala Krishna working as an Assistant Professor, Department of Mechanical Engineering, S.V. College of Engineering, Tirupati, Andhra Pradesh, 517520, India.

M. Peeraiah working as an Assistant Professor, Department of Mechanical Engineering, S.V. College of Engineering, Tirupati, Andhra Pradesh, 517520, India. 